\title{
Quantitative Volumetric Analysis Post Transsphenoidal Pituitary Adenoma Surgery
}

\author{
Alireza Mansouri, Sean Symons, Michael Schwartz, Joseph Chen, \\ Farhad Pirouzmand
}

\begin{abstract}
Background: Computed tomogram (CT) imaging is often used for immediate postoperative assessment of transsphenoidal pituitary adenoma resection while magnetic resonance imaging (MRI) is used for follow-up. The residual mass is known to decrease in size over time but the difference between the two imaging modalities has not been quantified. Our objective was to quantify the size difference of the residual mass on immediate postoperative CT compared with delayed MRI. Methods: Retrospective analysis of 69 patients who had undergone pituitary adenoma resection at our institution between 2004-2010. Sellar and suprasellar diameter, along with the overall volume of the residual mass were measured on both the immediate postoperative CT and delayed MRI. Results: Average preoperative sellar and suprasellar diameter was $22.2 \pm 4.6 \mathrm{~mm}$ and $20.9 \pm 5.9 \mathrm{~mm}$, respectively. Average sellar residual diameter on immediate postoperative CT $(16.5 \pm 5.4 \mathrm{~mm}, 25 \%$ reduction) was significantly larger than delayed MRI (10.6 $\pm 6.2 \mathrm{~mm}$, $52 \%$ reduction). The average suprasellar component on CT $(15.5 \pm 6.5 \mathrm{~mm}, 26 \%$ reduction) was also significantly larger than that on MRI $(3.3 \pm 5.4 \mathrm{~mm}, 84 \%$ reduction). The postoperative CT showed a $46 \%$ reduction in volume while a $71 \%$ reduction was noted on the delayed MRI. Conclusion: A significant reduction in residual mass is noted on delayed MR imaging compared with immediate postoperative CT. Therefore, from a resource management and prognostication point of view, CT should be used for immediate postoperative assessment while delayed MRI should be used to assess operative success and for communication with patients.
\end{abstract}

RÉSUMÉ: Analyse volumétrique quantitative après la chirurgie par voie transsphénoïdale pour un adénome pituitaire. Contexte : La tomodensitométrie est souvent utilisée pour l'évaluation du résultat de la résection transsphénoïdale d'un adénome pituitaire immédiatement après la chirurgie alors que l'imagerie par résonance magnétique (IRM) est utilisée pour le suivi de ces patients. On sait que la masse résiduelle de la tumeur diminue avec le temps, mais la différence entre les deux techniques d'imagerie n'a pas été quantifiée. Notre objectif était de quantifier la différence de taille de la masse résiduelle entre la tomodensitométrie effectuée immédiatement après la chirurgie et l'IRM effectuée par la suite. Méthode : Nous avons effectué une analyse rétrospective des données de 69 patients qui avaient subi une résection d'un adénome pituitaire dans notre institution entre 2004 et 2010. Le diamètre de la selle turcique et le diamètre suprasellaire ainsi que le volume total de la masse résiduelle ont été mesurés sur la tomodensitométrie effectuée immédiatement après la chirurgie et sur l'IRM effectuée par la suite. Résultats : Le diamètre sellaire et suprasellaire moyen avant la chirurgie était de 22,2/4,6 $\mathrm{mm}$ et $20,9 / 5,9 \mathrm{~mm}$ respectivement. Le diamètre sellaire résiduel moyen à la tomodensitométrie effectuée immédiatement après la chirurgie (16,5/5,4 mm, diminution de $25 \%)$ était significativement plus grand qu'à l'IRM effectuée par la suite (10,6/6,2 mm, diminution de 52\%). La composante suprasellaire moyenne à la tomodensitométrie (15,5/6,5 mm, diminution de 26\%) était également significativement plus grande qu'à l'IRM (3,3/5,4 mm, diminution de $84 \%)$. La tomodensitométrie postopératoire montrait une diminution de $46 \%$ du volume alors que cette diminution était de $71 \%$ à l'IRM effectuée au cours du suivi. Conclusion : On observe une diminution significative de la masse résiduelle à l'IRM effectuée au cours du suivi par rapport à la tomodensitométrie effectuée immédiatement après la chirurgie. Afin d'assurer une bonne gestion des ressources et pour établir le pronostic, la tomodensitométrie devrait être utilisée pour l'évaluation postopératoire immédiate alors que l'IRM devrait être utilisée pour évaluer le résultat opératoire et pour communiquer ce résultat au patient.

Can J Neurol Sci. 2012; 39: 600-604

Pituitary adenomas comprise $10 \%$ of all surgically-resected intracranial tumors ${ }^{1}$. The overall age-adjusted incidence is about $0.9 / 100,000$ person-years ${ }^{2}$. These tumors can be resected from a variety of approaches, of which the trans-sphenoidal method is the most common and has the lowest complication rate ${ }^{3}$. There are variations in the trans-sphenoidal approach, mainly differing in the access to the sphenoid sinus or visualization technique used during resection.

At our institution, computed tomogram (CT) imaging is used to monitor the progress of pituitary tumors preoperatively. Magnetic resonance imaging (MRI) is used prior to surgical intervention to assess the intimate association of the lesion with surrounding neuronal and vascular structures. In the immediate postoperative period $\mathrm{CT}$ is used to assess for complications

From the Division of Neurosurgery (AM, FP), Division of Neuroradiology (SS), Division of Otolaryngology - Head and Neck Surgery (MS, JC), Sunnybrook Hospital, University of Toronto, Toronto, Ontario, Canada.

Received January 4, 2012. Final Revisions Submitted March 8, 2012. Correspondence to: Alireza Mansouri, Division of Neurosurgery, Hospital for Sick Children, 555 University Avenue, Suite \# 1503, Toronto, Ontario, M5G 1X8, Canada. Email: alireza.mansouri@utoronto.ca. 
while delayed (three to four months) MR imaging is used to assess for extent of tumor resection. Computed tomogram imaging is a quick, easily accessible, and cost effective imaging modality. However, due to the presence of bony structures surrounding the pituitary gland, the resolution attained through CT imaging is sub-optimal. This is further affected by the postoperative changes within the sella which make it difficult to identify the extent of tumor resection and the amount of residual tumor. In some cases, the immediate postoperative CT may even suggest enlargement of the sellar mass and increased suprasellar extension, despite resection of tumor. This could be related to local hemorrhage, swelling of surrounding tissues, or packing material during surgery ${ }^{4}$. Furthermore, a study by Kaplan et al, with variable follow-up ranging from 39 days to 56 months, suggested that up to $81 \%$ of abnormal sellar enhancement on CT in the immediate postoperative period was associated with tumor recurrence $^{5}$. Therefore, surgeons may be faced with the difficult decision of having to perform a second operation in the immediate postoperative period based on the early CT scan result alone. In addition, the early appearance of CT scan can further affect the communication of prognostic information to patients and their families.

Magnetic resonance imaging can help distinguish residual tumor from hemorrhage, edema, or hemostatic packing material such as gel foam, muscle or fat plugs ${ }^{6,7}$. A small study by Rodriguez et al. has shown that the aforementioned components contribute to the apparent enlargement of the sellar mass that is seen in the first postoperative week. The authors have gone on further to observe on MRI that the material is gradually absorbed over time and reaches a stable size by the fourth post operative month $^{7,8}$. This is within the range that most follow-up MRI are obtained. Although MRI has emerged as a more sensitive method for assessing the success of pituitary adenoma resection in the early stages, there is expected variable reduction in the overall size of residual mass at the operative site. There have been no formal quantitative studies to define the expected change over time between early imaging (first day) and delayed imaging (three to four months) post surgery. This study attempts to quantify the average expected change between early and late imaging after trans-sphenoidal pituitary tumor resection using the two imaging modalities. While a quantitative comparison between the same imaging modality would yield a more accurate assessment of the difference in the size of the residual mass, we selected this method based on the standard practice at our institution which we feel is the most resource-effective strategy.

\section{Methods}

\section{Design}

A retrospective analysis of all patients who had undergone trans-sphenoidal pituitary adenoma resection at our institution between 2004 and 2010 was performed $(n=69)$. Repeat operations were excluded due to inherent expected difficulties in assessing the imaging findings. Only those who had complete imaging series (immediate pre-operative CT, first day postoperative CT, and delayed post-operative MRI (three to four months) were included $(\mathrm{n}=47)$.

\section{Measurements}

Preoperative imaging was performed on a General Electric Lightspeed CT, either 4 or 64 detector. The slice thickness was $2.5 \mathrm{~mm}$. Fiducial markers were placed on the head. $100 \mathrm{cc}$ of intravenous contrast was administered (Omnipaque 300). Postoperative CT was performed on the same scanners, without and with intravenous contrast, on the first postoperative day. The slice thickness of the postoperative scans was $5 \mathrm{~mm}$. Postoperative MRI was performed three months post surgery on a General Electric 1.5T MR or a Philips 3.0T MR. Sagittal T1, coronal T1, coronal T2, sagittal T1 post gadolinium, and coronal $\mathrm{T} 1$ post gadolinium images were obtained. The slice thickness was $3 \mathrm{~mm}$ with a space of $0.3 \mathrm{~mm}$ between slices. Gadolinium dose was $0.1 \mathrm{mmol}$ per kilogram.

Three measurements were used to analyze the size of residual pituitary mass: The largest transverse diameters of the sellar and suprasellar components, in addition to the overall volume of the residual mass. The sellar size was measured as the axial diameter of the tumor at the level corresponding to one cut below the anterior clinoid. The suprasellar size was measured as the axial diameter of the tumor at the level of the carotid terminus, which approximates the location of the chiasm and therefore a functionally-important segment to analyze. In cases where the termination occurred at different levels on one side compared to the other, the average size of both cuts or the size in the axial cut in between (if present) was measured. In situations where the residual mass of interest was not contained within one entity in the measured plane, the segmental diameters were measured separately and added as if they were continuous. Coronal MRI was used to obtain postoperative residual mass measurements. To identify the mass on MRI, T1 images with gadolinium enhancement were primarily assessed, with T2 images used only for verification.

Given that over time the suprasellar component has the potential to sink into the sellar region and affect transverse diameter measurements, we also compared the volume of the mass on CT and MRI as well, using the Osirix ${ }^{\mathrm{TM}}$ version 3.9 software. Briefly, the area of the mass within each slice was outlined and the 3D volume computation function of the software was used to calculate the volume and obtain a 3Drendered image of the mass.

\section{Analysis}

Analysis of average values was restricted to the patients in whom the postoperative CT showed a residual mass in the sellar or suprasellar regions; patients in whom no mass was detected on the postoperative CT were excluded from comparison. This resulted in the attainment of a more meaningful standard deviation. Two-tailed Students't-test was used to assess statistical significance. Differences were deemed to be significant at a p-value of $\leq 0.05$.

This study was approved by the institutional research ethics board at Sunnybrook Health Sciences Centre.

\section{RESUlts}

Overall 47 patients were analyzed, one was excluded from the final comparison given that there was no residual mass on the post operative CT (Table 1). A residual was detected on delayed 
Table: Assessment of the greatest transverse diameter in the sellar and suprasellar regions and the overall volume

\begin{tabular}{|c|c|c|c|}
\hline & $\begin{array}{c}\text { Average } \\
\text { Pre op CT }(\mathbf{m m})\end{array}$ & $\begin{array}{c}\text { Average } \\
\text { Post op CT mm } \\
\text { (\% reduction) }\end{array}$ & $\begin{array}{c}\text { Average } \\
\text { Post op MRI mm } \\
\text { (\% reduction) }\end{array}$ \\
\hline Sellar diameter & $22.2 \pm 4.6$ & $16.6 \pm 5.4$ & $10.6 \pm 6.2$ \\
\hline $\begin{array}{r}\text { Seen on both post-operative } \\
\text { CT and MRI }(n=39)\end{array}$ & $22.6 \pm 4.7$ & $\begin{array}{r}17.2 \pm 5.2 \\
(24 \%)\end{array}$ & $12.2 \pm 4.8(46 \%)$ \\
\hline $\begin{array}{r}\text { Seen only on post-operative } \\
\text { CT }(n=7)\end{array}$ & $19.6 \pm 2.5$ & $\begin{array}{r}12.7 \pm 5 \\
(35 \%)\end{array}$ & $\begin{array}{r}0 \\
(100 \%)\end{array}$ \\
\hline Supra sellar diameter $(\mathrm{n}=25)$ & $20.9 \pm 5.9$ & $15.5 \pm 6.5$ & $3.3 \pm 5.4$ \\
\hline $\begin{array}{r}\text { Seen on both post-operative } \\
\text { CT and MRI }(n=8)\end{array}$ & $25.2 \pm 5.5$ & $\begin{array}{r}18.8 \pm 6.9 \\
(25 \%)\end{array}$ & $\begin{array}{r}9.8 \pm 4.7 \\
(61 \%)\end{array}$ \\
\hline $\begin{array}{r}\text { Seen only on post-operative } \\
\text { CT }(n=17)\end{array}$ & $19 \pm 5.2$ & $\begin{array}{r}14 \pm 6.0 \\
(26 \%)\end{array}$ & $\begin{array}{r}0 \\
(100 \%)\end{array}$ \\
\hline Volume $\left(\mathrm{cm}^{3}\right)$ & $6.3 \pm 4.5$ & $3.4 \pm 2.6$ & $1.6 \pm 1.5$ \\
\hline
\end{tabular}

mm: millimeters; cm: centimeters; CT: Computed Tomography; MRI: Magnetic Resonance Imaging; Op: operative

MR imaging in 39 of these cases. In the suprasellar region, postoperative CT detected 25 patients with a residual mass while follow up MRI only confirmed 8 of these. The person obtaining the measurements was blinded to the final outcome of the procedure. Inter-observer variability was within $5 \%$ based on a random assessment of ten images by a second independent observer.

\section{Transverse diameters}

The immediate postoperative CT showed an average residual sellar mass of $16.5 \pm 5.4 \mathrm{~mm}$ (median $=16.5 \mathrm{~mm}$, range 5 $28.8 \mathrm{~mm}$ ). At an average of $10.6 \pm 6.2 \mathrm{~mm}$ (median $=10.7$, range $0-22 \mathrm{~mm}$ ), MRI demonstrated that a significantly smaller mass was present than had originally been measured based on the CT $(\mathrm{p}<0.001)$. This pattern was identified within the suprasellar region as well. At an average size of $3.3 \pm 5.4 \mathrm{~mm}$ (median $=0$
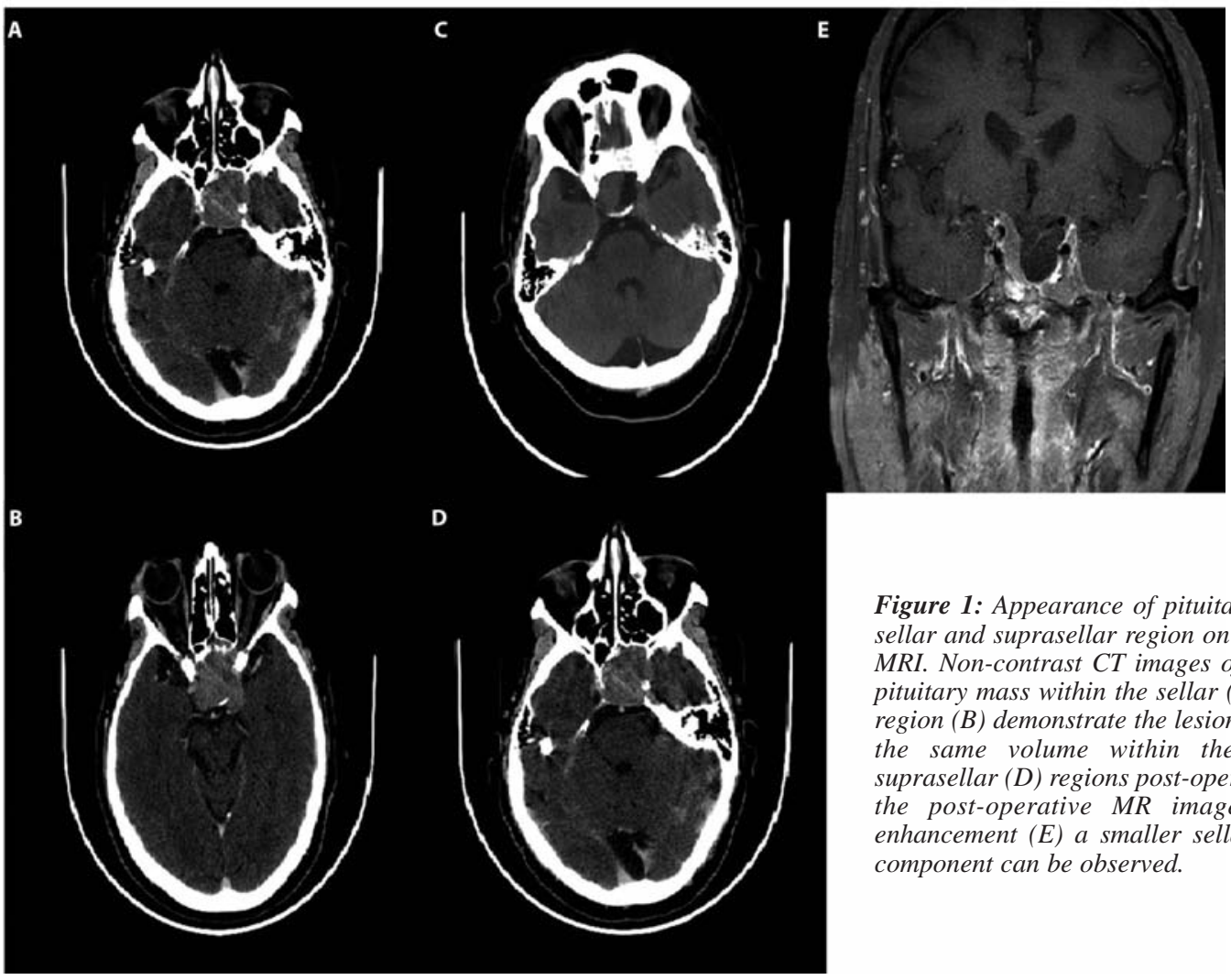

Figure 1: Appearance of pituitary mass within the sellar and suprasellar region on CT compared with MRI. Non-contrast CT images of the pre-operative pituitary mass within the sellar $(A)$ and suprasellar region $(B)$ demonstrate the lesion to roughly occupy the same volume within the sellar $(C)$ and suprasellar $(D)$ regions post-operatively as well. On the post-operative MR image, T1 with GAD enhancement (E) a smaller sellar and suprasellar component can be observed. 
$\mathrm{mm}$, range $0-18.2 \mathrm{~mm}$ ), the MR image showed a significantly smaller mass within this region compared with the $15.5 \pm 6.5 \mathrm{~mm}$ (median $=15.6 \mathrm{~mm}$, range $4.4-28.9 \mathrm{~mm})$ observed on the immediate postoperative CT $(\mathrm{p}<0.001)$. A sample case has been illustrated in Figure 1, visually demonstrating the disparity between the two imaging modalities.

We further elaborated the analysis to determine whether the size of the residual on the postoperative CT (whether sellar or suprasellar) could help predict the presence of a residual mass on follow up MRI. To this end, the categories noted in the table were further divided into subcategories: those that only showed a residual on the CT (not the MRI) and those that showed a residual on both $\mathrm{CT}$ and MRI. A non-significant difference was noted in cases where a suprasellar component was only present on the postoperative CT. However, in the sellar region, the mass was on average significantly larger $(\mathrm{p}=0.04)$ when both imaging modalities agreed $(17.2 \pm 5.2 \mathrm{~mm})$ as opposed to when it was only evident on CT $(12.7 \pm 5 \mathrm{~mm})$. Although this quantitative result further supports the notion that the larger the postoperative residual, the more likely it is to be a true remnant of the tumor, our experience shows that evidence of invasion into parasellar structures, such as the cavernous sinus or the encasement of the carotid arteries, was a better predictor of actual tumor residual. In our analysis, the follow-up MRI confirmed residual tumor in all 16 cases where parasellar invasion was noted on the immediate postoperative CT.

\section{Volume measurement}

Measurement of the transverse diameter of residual tumor components is a simple and quick method of assessing operative success. However, due to the anticipated inaccuracies of a twodimensional measurements and the likelihood of mass shifting during the follow-up period, we determined that volumetric measurements would serve as a more accurate predictor of residual mass. Similar to observations in the diametric measurements, the volume of the residual mass was significantly smaller on the immediate postoperative CT compared with the preoperative volume $\left(3.4 \pm 2.6\right.$ vs $\left.6.3 \pm 4.5 \mathrm{~cm}^{3}, \mathrm{p}<0.001\right)$ but this was still significantly larger than the volume on the MRI $\left(1.6 \pm 1.5 \mathrm{~cm}^{3}, \mathrm{p}<0.001\right)$. Figure 2 depicts this finding graphically, in the same patient noted in the previous figure. A significant decrease in the suprasellar component of the mass can be noted on the MR image. Also, as mentioned in the above observations, the segment of the mass encasing the right carotid artery on the postoperative CT was noted on the follow-up MRI as well.

\section{DisCuSSION}

The complete resection of pituitary macroadenomas, especially those with parasellar invasion is not always attainable $^{9}$. The inability of the immediate postoperative CT to accurately assess for residual tumor has been described previously $^{6,10}$. More recent studies have demonstrated the advantage of MRI in detecting residual pituitary adenomas, given its ability to distinguish residual tumor from hemorrhage and packing material used intraoperatively ${ }^{7,11}$; nonetheless, it is not always easy to distinguish tumor from hemorrhage and fat packing even on MRI. At most centers, including ours, CT scanning continues to be utilized for the identification of immediate postoperative surgical changes and potential complications inherent to its ease of access and low $\operatorname{cost}^{6}$. In addition, within three to four months postoperatively, both CT and MRI have shown a decrease in the size of residual material within the operative site. In our analysis, by directly comparing immediate postoperative CT and follow-up MR (three to four months) in a relatively large sample of patients, we have been able to quantitatively show the striking difference between initial and follow-up imaging using the two different modalities. This difference was noted to be in the same range as that identified by Rodriguez and colleagues, comparing immediate and delayed MR imaging 7 .

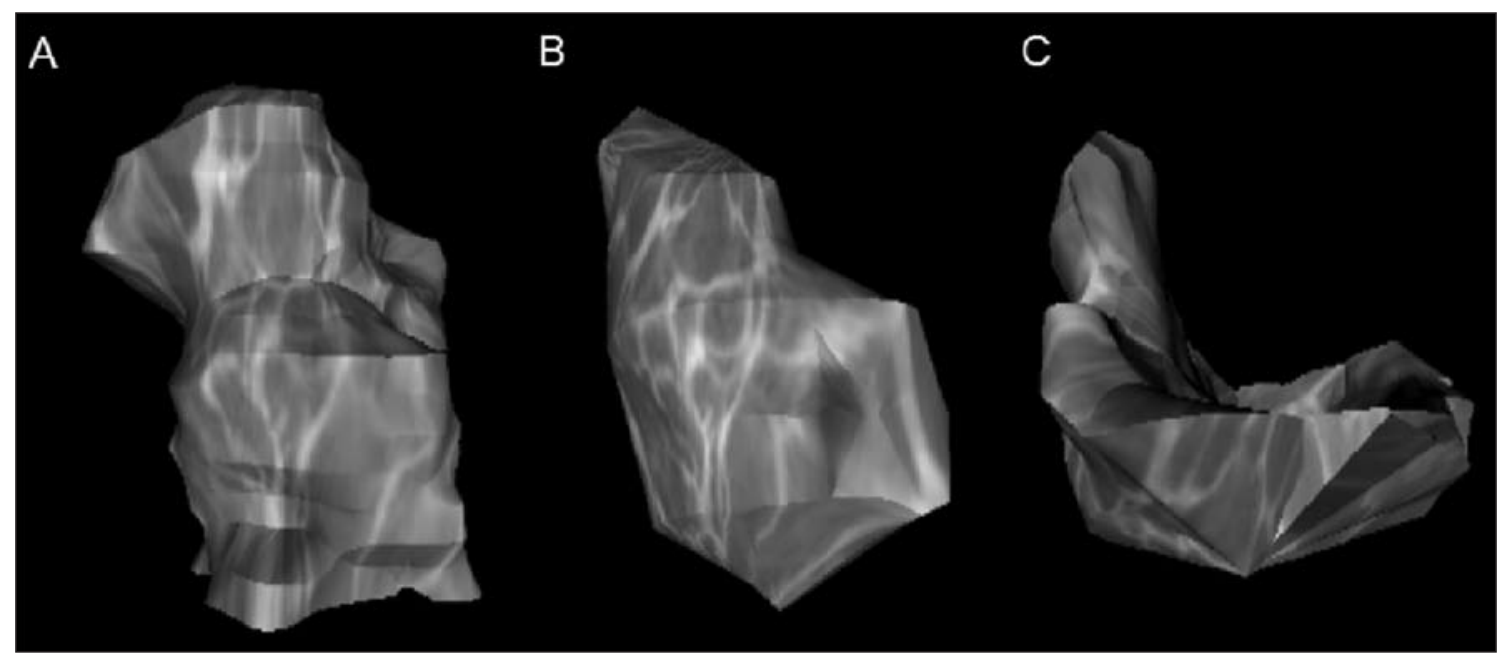

Figure 2: Volumetric analysis of the pituitary mass as observed on CT, compared with MRI. The 3 dimensional outline of the pre-operative pituitary mass observed on $C T(A)$ roughly resembles that of the immediate post-operative mass noted on $C T(B)$ as well. This residual mass, however, is strikingly smaller on the follow up MR image $(C)$. 
In the majority of cases, the presence of a suprasellar component observed on CT was either not detected on follow up MR or was significantly smaller. While a greater proportion of sellar residuals on the postoperative CT were confirmed on MRI as well, these were also significantly smaller. These observations make sense considering the superior resolution of MRI and the fact that blood, edema, and packing material are gradually absorbed over time. From a procedural point of view, the suprasellar region is more difficult to access. However, the suprasellar components will descend into the sella, whether intraoperatively or postoperatively, to fill the void left by the resected sellar mass. This helps explain why a sellar residual was found more commonly than a suprasellar residual in the immediate postoperative scan. Furthermore, it also explains why the relative reduction of the suprasellar component on MRI was found to be $84 \%$ compared to $52 \%$ for the sellar region. To account for the likelihood of the mass shifting from the suprasellar to the sellar region, the volumes were also assessed. These measurements reaffirm the previous findings.

Our study quantitatively highlights the significant reduction in the size of residual pituitary adenomas on delayed postoperative MRI compared with the immediate postoperative CT image. Along with the superior resolution of MRI, this lends further support to the notion of using MRI as the imaging of choice for following up patients with pituitary macroadenoma resections. Furthermore, these findings help to alleviate potential sources of concern for the surgeon. Often times, even though intraoperative findings may suggest a significant reduction of tumor mass, the postoperative CT scan can cast an element of doubt. Yoon and colleagues have recently used immediate postoperative MRI to detect residual masses, thus guiding early reoperation for residual tumor before fibrosis of the surrounding region could occur ${ }^{12}$. While this method theoretically improves the overall surgical cure rate, one must also consider the required resources for this endeavor and the risk that an additional operation poses to the patient. Of the total 83 patients analyzed in this study, only three underwent early reoperation based on MRI findings. Of these three, two required the operation secondary to hemorrhage and mass effect, findings that can be detected on early $\mathrm{CT}$ as well. Therefore, from a resource management point of view, the utility of early MRI for the assessment of complications and prognostication is questionable. Furthermore, based on our observations and the growing expertise of surgeons today, one is often able to gauge success based on the extent of visible tumor excised intraoperatively and knowledge of the preoperative tumor size. Immediate postoperative MRI is nonetheless highly valuable for the evaluation of cases in which there is concern regarding the invasion of delicate parasellar structures such as the carotid arteries and the cavernous sinus; thus, it is to the discretion of the surgeon to obtain this imaging modality in the early postoperative period.

The surgeon is required to rely on accurate information regarding operative success for further management planning. Like any other operation, patients and families are also anxious regarding the result of surgery and the long term prognosis of their illness. Based on our findings and the experiences of experts in the field, the immediate postoperative CT is most useful to assess for complications. However, the operative success and prognosis should only be cautiously evaluated with immediate postoperative CT. Immediate postoperative MRI will likely have similar limitations and may contribute to early unnecessary surgery and to the relaying of inaccurate information to patients. Therefore, it is advisable that final recommendations and plans of action be held until the follow-up MRI, obtained three to four months postoperatively. In the meantime, there is no substitute for good clinical, laboratory and ophthalmological follow up assessing the well-being and the functional status of the patient ${ }^{13}$.

\section{ConClusion}

In conclusion we have shown significant reduction in the size of the apparent residual mass after pituitary tumor resection over three months in the majority of patients. While our comparison was between CT and MR imaging, the amount of reduction noted was similar to that observed in studies comparing solely immediate and delayed MR imaging. This supports delaying any clinical or surgical decision making, with rare exceptions, until the first follow-up imaging within three months of operation. Nonetheless, CT imaging should still be utilized for the assessment of immediate postoperative complications.

\section{REFERENCES}

1. Saeger W, Lüdecke DK, Buchfelder M, Fahlbusch R, Quabbe HJ, Petersenn S. Pathohistological classification of pituitary tumors. 10 years of experience with the German Pituitary Tumor Registry. Eur J Endocrinol. 2007;156:203-16.

2. Surawicz TS, McCarthy BJ, Kupelian V, Jukich PJ, Bruner JM, Davis FG. Descriptive epidemiology of primary brain and CNS tumors: results from the Central Brain Tumor Registry of the United States. Neuro Oncol. 1999;1(14):1990-4.

3. Parrott J, Mullins ME. Postoperative imaging of the pituitary gland. Top Magn Reson Imaging. Jul 2005;16(4):317-23.

4. Teng MM, Huang CI, Chang T. The pituitary mass after transsphenoidal hypophysectomy. Am J Neuroradiol. 1988;9: 23-6.

5. Kaplan HC, Baker HL, Houser W, Laws ER, Abboud CF, Scheithauer BW. CT of the Sella Turcica after Transsphenoidal Resection of Pituitary Adenomas. Am J Roentgenol. Dec 1985; 145:1131-40.

6. Dolinskas CA, Simeone FA. Transsphenoidal Hypophysectomy: Postsurgical CT findings. Am J Roentgenol. Mar 1985;144: 487-92.

7. Rodriguez O, Mateos B, de la Pedraja R et al. Postoperative followup of pituitary adenomas after trans-sphenoidal resection: MRI and clinical correlation. Neuroradiology. 1996;38:747-54.

8. Steiner E, Knosp E, Herold CJ et al. Pituitary adenomas: findings of postoperative MR imaging. Radiology. 1992;185:521-7.

9. Ceylan S, Koc K, Anik I. Endoscopic endonasal transsphenoidal approach for pituitary adenomas invading the cavernous sinus. $\mathrm{J}$ Neurosurg. Jan 2010;112(1):99-107.

10. Ciric I, Mikhael M, Stafford T, Lawson L, Garces R. Transsphenoidal microsurgery of pituitary macroadenomas with long-term follow-up results. J Neurosurg. 1983;59:395-401.

11. Yoon PH, Kim DI, Jeon P, Lee SI, Lee SK, Kim SH. Pituitary adenomas. Early postoperative MR imaging after transsphenoidal resection. Am J Neuroradiol. Jun/Jul 2001;22: 1097-104.

12. Oyesiku N. Nonfunctioning pituitary adenomas. In: Rengachary S, Ellenhogen R, eds. Principles of Neurosurgery. Edinburgh; New York: Elsevier Mosby; 2005:598.

13. Rajaraman V, Schulder M. Postoperative MRI appearance after transsphenoidal pituitary tumor resection. Surg Neurol. 1999; 52(6):592-8. 